\title{
El Llibre d'amic e amat y el Llibre de les bèsties de Ramon Llull: una propuesta de lectura comparada
}

\author{
Ramon Llull's Book of the Lover and the Beloved and Book of \\ the Beasts: A proposal of comparative reading
}

\author{
CÉSAR GonZÁLEZ Álvaro \\ (Universidad Complutense de Madrid) \\ cesgon04@ucm.es \\ Recibido: Abril de 2017. Aceptado: Mayo de 2017
}

\begin{abstract}
Resumen: Valiéndonos del Arte como conector proponemos una lectura comparada entre dos de las obras breves más conocidas de Ramon Llull: el Llibre d'amic e amat y el Llibre de les bèsties. Prestamos atención a las fuentes y a los destinatarios de los textos así como a sus encuadres respectivos en el Romanç d'Evast e Blaquerna y en el Fèlix y a los distintos viajes que protagonizan sus personajes principales. Comparamos la figura del amigo y su fatigoso camino por el mundo con el recorrido realizado por Na Renart y las intrigas que desarrolla con su arte e ingenio, piezas fundamentales de lo que llamamos «contra-arte» por su relación con determinados aspectos del Arte luliano.
\end{abstract}

Palabras clave: Llibre de meravelles, Fèlix, Romanç d'Evast e Blaquerna, Arte, contra-arte, amigo, amado, Na Renart, dignidades, apostólicos.

\begin{abstract}
Using Art as a connector we propose a comparative reading between two of Ramon Llull's best-known short works: Book of the Lover and the Beloved and Book of the Beasts. We pay attention to the sources and receivers of the texts as well as their respective frames in Blaquerna and Fèlix and to the different trips that make their main characters. We compare the figure of the Lover and his weary road through the world with the route made by $\mathrm{Na}$ Renart and the intrigues that she develops with her art and ability, fundamental pieces of what we call «contra-art» because of their relationship with certain aspects of Llullian Art.
\end{abstract}

Keywords: Book of Wonders, Fèlix, Blaquerna, Art, contra-art, Lover, Beloved, Na Renart, Dignities, Apostolics. 
En el Llibre d'amic e amat encontramos una de las manifestaciones más perfectas del Arte en pleno funcionamiento dentro de un marco de ficción como es el viaje emprendido por el amigo en su ansiosa búsqueda de unión con el amado. El opúsculo, tras el que sigue el Art de contemplació que cierra el Romanç d'Evast e Blaquerna (1276-1283), es coherente con la carrera de Blaquerna, con su abandono del papado y su dedicación a una vida eremítica y a la educación de otros ermitaños a través de sus palabras y de esta suerte de manual místico «per lo qual puria muntiplicar frevor e devoció en los ermitans, los quals volia enamorar de Deu» (Llull 2009: 427). Su inserción, pues, no dejando de ser sorprendente está justificada en el conjunto de la novela y otro tanto sucede con el famoso Llibre de les bèsties, cuya inclusión en el libro VII del Fèlix o Llibre de meravelles (1287-1289), a pesar de su «soldadura un poc forçada» (Rubió i Balaguer 1985: 317), resulta lógica al mismo tiempo:

Així doncs aquest text sustenta una gran meravella i no és subsidiari ni marginal, de manera que es pot posar en paral-lel al tan important Llibre d'amic e Amat, enmig del Blaquerna; i si aquest Llibre d'alta mística dóna sentit i dinamisme a l'obra on s'inclou, podem pensar que també ho faci el Llibre de les bèsties respecte del Fèlix (Butinyà 2016: 397).

La fortuna tanto del Romanç d'Evast e Blaquerna como del Llibre de meravelles fue notable en su época si bien en el caso del primero la tradición manuscrita conservada en catalán es «força posterior als testimonis francesos, occitans o llatins més antics, alguns dels quals (...) són contemporanis de mestre Ramon» (Soler + Santanach 2009: 34), mientras que la trasmisión del Fèlix «occurred exclusively in Romance» (Badia et al. 2016: 115), conservándose doce manuscritos en catalán, siete medievales y cinco modernos (Bonillo 2015: 15-16). Por otro lado, no existen pruebas de que Ramon Llull (Ciudad de Mallorca, 1232-1316) emprendiera la escritura del Llibre d'amic e amat ${ }^{1}$ con anterioridad al Blaquerna y que pudiera ser añadido más tarde (Soler + Santanach 2009: 29), pero esta circunstancia sí que pudo darse con el Llibre de les bèsties en vista de las diferentes valoraciones de Fèlix respecto a la orden de los apóstoles y sería así una «obra precedent, escrita abans de la primera condemnació d'aquella secta pseudo-mística, és a dir, abans de l'11 de març del 1286» (Batllori 1993: 168).

Los viajes emprendidos por el amigo y Fèlix mantienen similitudes en cuanto a los tres objetivos primordiales del Arte, su triple naturaleza que nos permite distinguir entre un ««arte» para encontrar la verdad de tipo lógicometodológico (...), un «arte» de salvación, cuya finalidad es el conocimiento y la contemplación de Dios (...) y un «arte» para la conversión de los infieles, típico del «apóstol-polemista»» (Cruz Hernández 1977: 90). La actividad de predicación se manifiesta en dos distintas posibilidades:

${ }^{1}$ Con el fin de que la lectura sea más ligera se utilizará la abreviatura LAA y se indicará el versículo correspondiente en las citas del Llibre d'amic e amat. Para el Llibre de les bèsties la abreviatura será LB y se señalará la página de referencia. Las ediciones manejadas se pueden consultar en la bibliografía. 
La primera forma de predicación ad extra la llama Llull «mostrar via de veritat als infeels» y asoma en el Blaquerna y en el Fèlix, entre otros momentos, a través del famoso apelativo «precurador dels infeels» que Llull se da a sí mismo (...) La segunda forma de predicación es una predicación ad intra, es decir, de cara a los cristianos. Mientras la primera se relacionaba directamente con la demostración de los artículos de la fe, se centra la segunda en las virtudes y los vicios (Domínguez 2007: 137-138).

El viaje del amigo se muestra como un proceso esforzado, repleto de fatigas, largo y peligroso (LAA, 2, LAA, 205), recorrido por ciudades (LAA, 54, LAA, 179), vergeles (LAA, 157), «terres stranyes» (LAA, 161, LAA, 206) o por caminos que deben conducir hacia el amor del amado, auténtico objetivo del viaje. La búsqueda de su amor es constante y no tiene fin al igual que no existe un principio del que partir en una circularidad ascendente y descendente (LAA, 251), encontrando también placer en el sufrimiento (LAA, 189) y en la contrición (LAA, 42, LAA, 286). El intercambio de miradas es habitual, fatigosas y llorosas desde los ojos del amigo y cargadas de «dignitats divines» desde los ojos del amado mientras el simbólico pájaro canta el feliz encuentro (LAA, 41), pero asimismo hay desencuentros, eclipses y «tenebres» (LAA, 199), olvidos y recuerdos (LAA, 187) en unos juegos de amor y desamor (LAA, 49) sin presencia de erotismo. El amigo circula por paisajes alegóricos buscando el rastro del amor y hallándolo en todo cuanto ve y en sí mismo, lamentándose a su vez del olvido del hombre hacia su amado: «-Amat, qui tant has donat a home e tant 1'as honrat, per que home ha tant tu en ublit?-» (LAA, 211). Se asimilan en este viaje elementos de los característicos locus amoenus de la poesía provenzal, una tradición que Ramon Llull conocía y que practicó hasta su visión de Cristo en la cruz, decisiva en la posterior obra del beato: «La visión de la cruz es motor y explicación, pues en ella se genera la metáfora del árbol a la que va a adecuar su Arte o método» (Butinyà 2006: 21). El amor profano que cantan los trovadores se modifica por un amor a lo divino donde «la condició de possibilitat d'aquesta transposició és precisament l'existència d'una concepció més general i normativa de la naturalesa de l'amor (i, en concret, de l'amor d'amistat)» (Ruiz Simon 2015: 75). Por su lado, Fèlix recorre el mundo tras el encargo paterno que contiene un argumento querido por Ramon Llull como es la «primera intenció», en este caso en modo de queja por parte del padre de Fèlix y como motivación del viaje de su hijo:

Amable, fill, quaix morta es saviea, caritat e devoció e pochs son los homens qui son en la fi a la qual nostre senyor Deus los ha creats (...) Ve per lo mon e maravella.t dels homens per que sessen a amar e conexer e a loar Deu. Tota ta vida sia en Deu amar e conexer e plora per los falliments dels homens qui Deu ignoren e desamen (Llull 2011: 81).

Esta primera intención que motiva el viaje de Fèlix, maravillándose de su falta de cumplimiento por parte de los hombres, es inmanente en la ruta hacia las alturas que persigue el amigo en el Llibre d'amic e amat, el cual «és insistent i reiteratiu en la imatge de Déu com a suma de totes les perfeccions, com a l'amat perfecte al qual han d'anar destinats totes les activitats i els desitjos 
humans en primer lloc, d'acord amb la doctrina lul-liana de la primera intenció» (Luzón Díaz 2012: 115). Sin embargo, el viaje emprendido por Fèlix, con la conexión del Arte, será de distinta naturaleza que el del amigo y también que el de Blaquerna. En un hipotético orden de acercamiento a lo divino, Blaquerna -al que Llull atribuye la escritura del Llibre d'amic e amat- ocuparía el primer lugar, seguido por el amigo, quien está y no está junto al amado, pide descansos en sus fatigas - «Ublidar e innorar volgra l'amich son amat una ora tan solament, per ço que agués alcun repós a sos languiments» (LAA, 190)- y trata de tener acceso a Dios a través del entendimiento, la memoria y la voluntad (LAA, 163, LAA, 306, LAA, 326), concediendo a esta última cualidades de dirección (LAA, 219). El tercer lugar quedaría reservado para Fèlix, personaje que evoluciona a lo largo del texto con sus conversaciones con varios ermitaños y con el propio Blaquerna, a quien acude en compañía de una mujer que «havia perdut per mort un fill que molt amava e, per la yra que havia de la mort de son fill, anava a Blaquerna que li dixés paraules devotes e de consolaçió per tal que pogués haver conexença en la mort de son fill» (Llull 2011: 114). Blaquerna queda situado desde el primer momento en un lugar privilegiado como autoridad moral y su figura ejerce de contraste inmediato con las tentaciones que Fèlix tiene respecto a la mujer, cuyo piadoso discurso le sirve para reaccionar y dar un paso más en su aprendizaje:

E maravellá's com, dient la fembra aytals paraules, podia haver impaciencia I de la mort I de son fill ni com ell podia haver moviment de luxuria en peccar ab aytal fembra que tan sanctes paraules et tan devotes dehia de Deu (Llull 2011: 115).

El viaje del amigo se sustenta sobre una estructura de «metàfores morals». La intención inicial de Blaquerna es escribir tantos versículos «con ha dies en l'ayn» (Llull 2009: 429), aunque el número total resulta menor quizá porque «this short contemplative work was simply a fiction within the fiction» (Badia et al. 2016: 109) o por un «error de còpia de l'arquetip facilitada pel sistema ambigu de separació dels versicles que va utilitzar» (Soler + Santanach 2009: 67). Por su parte, el aprendizaje de Fèlix se articula mediante dos apoyos fundamentales como son la «meravella», cuya gama de matices y posibilidades es amplia - «extending from surprise and admiration to astonishment and consternation» (Badia et al. 2016: 118) - y la «semblança» que ofrece la solución al problema con analogías más o menos oscuras:

Tant l'una com l'altra fan sentit a partir de l'Art de Ramon, més concretament de l'Art demostrativa, esmentada quatre vegades a l'interior de l'obra (...) Abunden els casos d'identitat textual i conceptual amb aquesta i altres obres lul-lianes, especialment pel que fa als exemples de filosofia natural utilitzats en el sistema de correspondències analògiques entre els tres ordres de la realitat, material, espiritual i diví (Badia et al. 2011: 22).

El Arte, por tanto, en su segunda reformulación en el Art demostrativa (1283) como base sustentada por los exempla que contiene el Llibre de meravelles, el cual puede considerarse «un sermonario donde se reúnen una serie de 
temas de predicación ordenados según la scala creaturarum» (Domínguez 2007: 141). El catálogo de exempla es numerosísimo y su función contrasta con la que solía ocupar en los sermones clásicos:

De fet, la funció de l'exemplum en els sermons habituals era sempre subordinada a l'exposició doctrinal. La diferència és que ací, aquesta exposició ocupa un espai relativament petit $\mathrm{i}$, fins i tot, hi ha moments en què el diàleg esdevé un pur intercanvi d'exempla (Ysern 1999: 33, n. 17).

Todos los descubrimientos, nuevos conocimientos y aprendizajes de Fèlix se producen a través de esta herramienta, siguiendo al exemplum una explicación que «sempre té aquests dos moments: l'aclariment i l'aplicació» (Ysern 1999: 34). Se ilustra así el Arte en su versión cuaternaria, que se desarrolla tras la iluminación de Randa (1274) y cuya primera formulación si bien se halla en el Art abreujada d'atrobar veritat (1274) tiene el precedente del Llibre de contemplació en Déu (1271-1274): «Les dignitats presents al LC (Llibre de contemplació en Déu) s'organitzen en grups variables d'acord amb les necessitats argumentatives de cada capítol, amb uns esquemes més o menys repetits, i que en bona mesura anticipen la figura A de l'Aaav (Art abreujada d'atrobar veritat)»(Rubio 1997: 123). El posterior paso a la fase ternaria y «la reforma del sistema començà a Montpeller el 1290 i es completà el 1308 amb l'Ars generalis ultima, de la qual 1'Ars brevis és una versió compactada» (Badia et al. 2013: 388). El Arte recorre la vastísima producción del beato ${ }^{2}$ y su función queda explicitada claramente en el siguiente versículo del Llibre d'amic e amat: «Misatge era l'amich als princeps crestians e als infeels per son amat, per ço que·ls mostrás la art e·ls començaments a conexer, amar l'amat» (LAA, 137). Sin embargo, ¿qué sucede en el Llibre de les bèsties?

En las siguientes páginas nos adentraremos en las intrigas palaciegas que conforman el Llibre de les bèsties y en sus marcadas diferencias de clase dentro del sistema feudal. Nuestra lectura atenderá a las intervenciones más destacadas de los principales animales, pero sobre todo focalizaremos en $\mathrm{Na}$ Renart -personaje feminizado por Llull puesto que en la tradición del Roman de Renard era un zorro $^{3}$ - y los hilos que enreda y desenreda con su «art» y su «maestria» (LB, 238). Son estos unos atributos fundamentales en la figura de la zorra y en su recorrido escalador por las esferas de la política y, por tanto, son el apoyo central sobre el que se organizan sus discursos, que se sirven de conceptos relacionados con el Arte como, por ejemplo, la primera intención, el uso de distin-

${ }^{2}$ Respecto al Arte en las «metàfores morals» del Llibre d'amic e amat, la macroestructura circular del opúsculo, las estructuras igualmente circulares de muchos versículos, un análisis más detallado de las fuentes, la presencia de elementos neoplatónicos y también sobre el juego continuo con las tres potencias del alma de tradición agustiniana, me permito remitir a mi anterior trabajo: «Aproximaciones al viaje místico: Ramon Llull y San Juan de la Cruz», Revista de lenguas y literaturas catalana, gallega y vasca, 21, 2016, pp. 43-74.

3 «Observem, però, que si bé se li aplica un títol femení, $N a$, tal com l'animal guineu ho és en català, sovint Renard apareix concertant amb adjectius i participis o pronoms en masculí, conservant un rastre del gènere que porta gramaticalment en francès» (Rubió i Balaguer 1985: 319). 
tas dignidades o el poder de la palabra referida a Dios, la cual propicia su conocimiento y el acceso a la sabiduría en una circularidad justificada por el influjo divino. El personaje tiene la habilidad de recoger estas ideas y ponerlas a su servicio creando una especie de «contra-arte» que evoluciona y se adapta según lo requieren las circunstancias. Esta capacidad de adaptación es clave en su forma de obrar y veremos algunas piruetas en su razonamiento sin perder por ello coherencia -o, más bien, siendo lo suficientemente habilidosa para ocultarlo-, llegando incluso a deshacerse de sus cualidades básicas -la industria, la astucia...- cuando no le queda otra opción. En nuestra lectura iremos desgranando los componentes de este «contra-arte» y los enfrentaremos, en un ejercicio comparativo, con las apariciones del Arte en el Llibre d'amic e amat y sus aplicaciones prácticas en el viaje emprendido por el amigo. Esperamos así poder ofrecer unas comparaciones que, a modo de contraste, nos muestren los dos caminos tan alejados que recorren Na Renart y el amigo -la primera, un ascenso zigzagueante a través del poder político; el segundo, una búsqueda de ascensión hacia lo divino en una rueda de conocimientos y reconocimientos- y nos permitan, en fin, definir a este «contra-arte» como una suerte de negativo del Arte.

Hemos adelantado ya una de las fuentes del Llibre de les bèsties como es la serie de branches del Roman de Renard, cuya tradición se inicia en el siglo XII y que «no calia que Llull conegués durant les seves estades a París, car ja era molt divulgat a Catalunya (el citen Guillem de Berguedà i Cerverí) i contemporàniament (principi segle XIV) el castell d'Alcanyís era decorat amb frescos inspirat en el roman animalístic francès» (Riquer 1964: 313). Otra fuente conocida son «les intrigues fracassades de dos xacals a la cort del lleó, conegut al segle XIII a través d'una versió castellana de procedència àrab, el Calila i Dim$n a$, i de la traducció llatina del Directorium humanae vitae («Directori de la vida humana»), de Joan de Càpua» (Badia et al. 2013: 456), aunque también hay que tener en cuenta que «hom podria espigolar-hi encara altres influències orientals, que Ramon Llull rebria per mitjà de textos aràbics o bé d'aquella saviesa de l'Orient, exemplificada en la faula, que Isop i Fedre havien divulgat per tot el domini cultural de les llengües grega i llatina» (Batllori 1993: 170). En este breve capítulo de fuentes citamos por último las Cartas a Lucilio de Séneca, epístolas 85 y 90 (Butinyà 2008: 327 y ss.) y el Libro de los Jueces del Antiguo Testamento: «La semblança indicada es fa molt significativa en l'afrontament dels textos (...) a causa d'un matís ben curiós: les eleccions són democràtiques, car són obertes a la discussió i els participants hi opinen. Així doncs, hi exposen el seu parer un seguit d'animals a l'un, i qualques arbres i plantes a l'altre» (Butinyà 2016: 398).

La entrada en el mundo de las bestias, en lo que será una suerte de relato enmarcado, tiene lugar con el encuentro de Fèlix, mientras camina por un valle, con dos hombres «qui havien grans barbes et grans cabells et eren pobrament vestits» (LB, 221). Son estos dos hombres, de la orden de los apóstoles como sabremos a continuación, los que indican a Fèlix el camino hacia el mundo de las bestias: «En I aquella plana ha gran ajustament de besties salvatges qui volen elegir rey» (LB, 221). Desde el principio se establece, por tanto, una normalidad absoluta en cuanto a los comportamientos humanos de los animales. Fèlix 
ensalza el trabajo de quienes pertenecen a la orden de los apóstoles, aunque en su tono se percibe una alabanza condicionada y una advertencia (Butinyà 2016: 409). Los dos apostólicos reconocen no ser dignos de comparación con los apóstoles, pero afirman representarlos con una serie de valores muy cercanos al Arte:

Nos havem esperança en Deu que ell trametrá holmens de santa vida en lo mon, los quals sien de l'orde dels apostols, e que aquells hajen sciençies et lenguatges on sapien preycar et convertir los infeels per ajuda de Deu, e als crestians donen bon eximpli per vida e per santes paraules; et per tal que Deus se.n mova a pietat e que los homens qui son crestians desigen l'aveniment d'aytals homens, representam en figura los apostols (LB, 222).

Estos dos apostólicos explicitan así las tres funciones del Arte como método de conocimiento y descubrimiento de la verdad, herramienta de conversión para «los infeels» y ejemplo para los «crestians» y lo hacen con una curiosa confianza futura en que vengan otros hombres con esas cualidades. Señalan, además, la importancia de conocer «sciençies» y «lenguatges», indispensables para la comunicación del Arte, y exaltan la devoción en la palabra, la cual a su vez origina expresamente el Llibre d'amic e amat cuando Blaquerna recuerda lo dicho por un sarraceno refiriéndose a los sufíes:

E aquells han paraules d'amor e exemplis abreuyats e qui donen a home gran devoció; e son paraules qui han mester espusició e per | la spusició | puja l'enteniment mes a ensús, per lo qual puyament muntiplica e puja la volentat en devoció (Llull 2009: 427)

Blaquerna, pues, emprende la escritura del opúsculo con una confianza que radica en el poder de la palabra y en su capacidad para producir efectos en las potencias del alma que conlleven un acercamiento a lo divino. Volviendo al encuentro de Fèlix con los apostólicos, J. Butinyà (2016) propone una nueva lectura en clave histórica que afecta tanto a esta escena como al resto de la obra -y al Fèlix en su conjunto- al apuntar hacia los Apostoli como posibles destinatarios del texto. Si bien el Llibre de les bèsties finaliza con una declaración que lo acerca a su posible función como «espejo de príncipes» ${ }^{4}$, también cabe la posibilidad de que su audiencia fuera más concreta y estuviera oculta en lo que sería un nuevo juego literario que no sería extraño en Ramon Llull. De esta manera, «amb ocasió de l'elecció del General del franciscans, Llull aprofitaria per alliçonar els apostòlics, als quals té ben presents al Fèlix, obra que redactava per aquelles dates. I al damunt del sòlid canemàs d'un apòleg bíblic, els dedica-

${ }^{4}$ El Llibre de les bèsties se cierra con un epílogo que «pot estar relacionat amb el fet que Llull va tenir contactes amb la cort de Felipe IV de França els anys de la redacció del Fèlix, quan aquest rei era prop de la vintena, i hauria pogut ser-ne el destinatari» (Badia et al. 2013: 456). El epílogo es el siguiente: «Ffenit es lo "Libre de les besties", lo qual Felix portá ha un rey per tal que veés la manera segons la qual, en ço que fan les besties, es significat com rey deja regnar e-s deja guardar de malvat consell et de falsos homens» (Llull 2011: 269). 
ria d'amagat una faula, bastida amb dues belles i alhora encobridores fonts literàries, oriental i francesa: el Llibre de les bèsties» (Butinyà 2016: 413). Y en lo que respecta a la escena de Fèlix con los apostólicos, relacionada con el inicio del Llibre d'amic e amat, «observem que si al súmmum de la vida contemplativa Llull havia situat els sufís, al de la vida activa encimbellaria aquest franciscans, i que tots dos col-lectius religiosos pertanyen a cercles compromesos a almenys sospitosos» (Butinyà 2016: 398).

Fèlix deja atrás a los apostólicos y se encamina hacia el reino de los animales situado en un tranquilo locus amoenus trovadoresco, una «bella plana, per on passava una bella aygua» (LB, 223), lugar que luego no será nada pacífico. Fèlix desaparece de la acción -permanecerá únicamente como observador en la sombra hasta el epílogo- y entramos en lo que antes llamábamos el «relato enmarcado» de los animales, quienes se hallan inmersos en un proceso de votación para elegir rey. Aparece pronto la gran división entre las bestias que comen carne y las que se alimentan sólo de hierba -y dentro de ambas categorías unas nuevas subdivisiones respecto al tamaño de los animales-, lo que condiciona y marca sus intereses y posibilidades. El Buey se opone al reinado del León y afirma que «a noblea de rey se cové bellea de persona e que sia gran et humil et no do dampnatge a ses gents» y propone al Caballo: «lo Cavall es gran bestia et humil; lo Cavall es bestia leugera et no ha semblant ergullós ni no menuga carn» (LB, 223). Esta identificación entre bondad y belleza, de tinte neoplatónico, es un recurso recurrente en la literatura de Ramon Llull:

El mensaje fundamental de la predicación luliana es la exigencia de entender y llegar a comprender cómo lo bueno y lo bello que llega a nosotros a través de los sentidos nos da la posibilidad de llegar al verdadero y recto juicio. Entre los sentidos y el recto juicio sobre las cosas juega un papel decisivo la imaginación que actúa a través de las semblances/similitudines (Domínguez 2007: 143-144).

Las cualidades atribuidas al Caballo nos llevan a pensar en la utilización de ciertas dignidades en las palabras del Buey. En el Llibre d'amic e amat la presencia de las «dignitats divines» acompaña al amigo durante su recorrido y accede a ellas $-\mathrm{y}$ también se aleja- a través de tres vías que se relacionan: los sentidos físicos, los cinco sentidos espirituales y la memoria, el entendimiento y la voluntad, de tal forma que «partint de les captacions sensuals, l'amic es veu en condicions d'enlairar la seua memòria i el seu enteniment a la consideració de les realitats morals que li poden resultar perjudicials, atès que s'oposen als designis divins» (Luzón Díaz 2010: 50). Las «dignitats divines», sujetas a variaciones en las distintas versiones del Arte, aparecen en multitud de versículos en los que el amigo ensalza la nobleza del amado (LAA, 24), su «justicia, prudencia, fortitudo, temprança» (LAA, 78), acumulaciones de virtudes como «granea, poder, saviea, amor, perfecció» (LAA, 37) o «nobles dons» provenientes de amor como «leyaltat, sperança, paciencia, devoció, fortitudo, temprança, benanança» (LAA, 106). Con lo dicho por el Buey están de acuerdo todos los animales que comen hierba. Na Renart, auténtica protagonista del libro y único personaje con nombre propio, interviene con unas palabras en donde aprovecha 
la primera intención luliana para su propósito, que no es otro sino marcar claramente el estamento de cada cual, es decir, primero los animales carnívoros y luego los herbívoros:

- Senyors -dix Na Renart-, com Deu creá lo món, no·l creá per entenció que home fos conegut ni amat, ans o feu per ço que ell fos amat et conegut per home; e segons aytal entençió, Deus volch que home fos servit per les besties, jatsia que home viva de carn e d'erbes. E vosaltres, senyors, no devets esguardar I a la entençió del Bou, que desama lo Leó per ço que menuga carn, ans devets seguir la retgla e la ordenança que Deus ha donada e posada en les creatures (LB, 223-224).

La escala que dibuja no puede ser más directa y no le importa reconocer una inferioridad hacia el hombre para quedar ella situada en una mejor posición. Tiene una clara conciencia de la clase a la que pertenece, de su lugar en el mundo entre unos y otros, pues, aun siendo carnívora, parece que Na Renart ocupa un espacio a modo de bisagra en el que se incrementa su capacidad para crear intrigas. Valiéndose entonces del argumento lineal de la primera intención, nos da una primera muestra de su «contra-arte», de su capacidad para recoger determinadas ideas y ponerlas a su servicio, unas veces con intención política y otras únicamente vengativa. En este caso la servidumbre y la gradación que invoca - «la retgla e la ordenança que Deus ha donada e posada en les creatures»-ciertamente resultan muy convenientes para ella. Por otro lado, como comentábamos anteriormente, en el Llibre d'amic e amat se insiste continuamente en la obligación del hombre en su servicio hacia Dios. Lo vemos en el siguiente versículo con el amigo defendiendo la primera intención y reconociendo los esfuerzos que supone su servidumbre:

—Digues, foll, vols esser franch de totes coses?

Respós que hoc, eceptat son amat.

-Vols esser catiu?

Respós que hoc: -De suspirs e pensaments, treballs e perills e exils, plors, a servir mon I amat, al qual son creat per loar ses valors (LAA, 236).

En la naturaleza del amigo son inmanentes, pues, las torturas (LAA, 105), los sufrimientos (LAA, 102), los escarnios ( LAA, 142) y las fatigas en las que experimenta también gozo en un mezcolanza de sentimientos: «E per açó, en totes maneres a l'amich per son amat amors e treballs e languimens e plaers e consolacions» (LAA, 320). Su relación con el resto de criaturas se da en ocasiones a través de la imaginación (LAA, 323), la cual partiendo del amor puede rastrear las huellas del amado a su alrededor (Cruz Hernández 1977: 281). Al igual que todo, las criaturas llevan el sello divino -«E qui es ton maestre? Respós e dix que les significançes que les creatures donen de son amat» (LAA, 57)-, lo que le permite, por ejemplo, conversar con el pájaro sin palabras mediante el amor que les une (LAA, 27) e incluso recurrir a él en buscas de respuestas: 
Digues, aucell qui cantes d'amor al meu amat, per que.m turmenta ab amor qui m'a pres a esser son servidor?

Respós l'aucell: - Si no sostenies treballs per amor, ab que amaries ton amat? (LAA, 35).

Regresamos al Llibre de les bèsties, donde la intervención de la zorra encuentra réplica en el Buey: «Na Renart mes vol I que lo Leó sia rey per ço cor viu de les romanalles que romanen al Leó com ha menjat en la caça que ha presa, que no fa | per la noblea del Leó» (LB, 224). Se explicitan así sus verdaderas intenciones y su posición queda reafirmada, como decíamos antes, a medio camino entre dos polos opuestos. Las elecciones son interrumpidas y Na Renart actúa con un movimiento idéntico que el del Buey hacia ella, pero revelando las intenciones de otros que le preocupan más por sus aspiraciones reales como son el Oso, el Leopardo y la Pantera. Lo hace a través de un exemplum sobre las elecciones para obispo en una catedral y las intrigas para conseguir el puesto, buscando un golpe de efecto al introducir un segundo ejemplo dentro del anterior en el que la participación de un canónigo será decisiva:

Si lo Leó es rey, et l'Ors I et la Onssa et el Leopart han contrast a la elecció sua, tots temps seran en malvolença del rey. E si lo Cavall es rey et lo Leó fa negun falliment contra 1 rey, com ne porá pendre venjança lo Cavall, qui no es tant forts bestia com es lo Leó? (LB, 224).

Na Renart señala así a sus enemigos dentro de un nuevo marco de ficción. El movimiento resulta mucho más efectivo que el del Buey con su revelación y se termina imponiendo la ley del más fuerte. El León es coronado e inmediatamente, sin ningún tipo de transición, «doná licencia a totes les besties qui menuguen carn, que menjassen et vivissen de les besties qui menuguen erba» (LB, 225), con lo cual las anteriores elecciones toman un cariz oscuro, la sensación de que el juego estaba amañado de antemano y en el fondo todo no era más que un teatrillo puesto que, bajo aquellas circunstancias, ¿cómo hubiera podido ser rey un animal menos fuerte? La forma de actuar en el reino queda plasmada pronto cuando el rey y el resto de animales carnívoros tienen hambre y el Lobo y Na Renart lo organizan de tal modo que se comen a los hijos del Buey y del Caballo, quienes irán a servir al hombre y no tendrán demasiada suerte bajo su dominio. El posterior encuentro entre ambos nos expone su penosa situación y sirve de introducción a la figura del hombre. El consejo del Caballo hacia el Buey es que huya y que regrese, «cor mes li valia estar en perill de mort en repós et enfre sos parents, que en perill de mort ne en treball et ab senyor desconexent» (LB, 226).

La trama del Llibre de les bèsties se enriquece con la necesidad, expresada por el rey, de repartir responsabilidad en su gobierno, con lo cual se procede a la elección de los consejeros. Na Renart no es elegida y sabe que necesita una actuación potente para cambiar las cosas, por lo que abre su discurso apoyándose en el «Avengeli» (LB, 227) para traer a colación el que Jesucristo se rodeara de hombres simples, humildes y pobres como los apóstoles, de tal forma que, declara la zorra, «a mi seria semblant que el rey I degués haver en son consell 
besties simples et humils» (LB, 228). Vemos, por tanto, cómo el personaje es capaz de cambiar velozmente de bando o, más bien, actúa como quien reparte cartas marcadas para conseguir una victoria propia o la de quien le conviene en ese momento. Su «contra-arte» es flexible y permite estos cambios de tono y posición. Valiéndose de dos equivalencias -Jesucristo y el rey, los apóstoles y el Consejo- reivindica una condición de pobreza que le resulta muy oportuna y dos dignidades divinas como son la humildad y la sencillez. Entre estas dos dignidades existe, además, una relación de intercambio en el Arte luliano y así R. Luzón (2012) las incorpora al catálogo de dignidades presentes en el Llibre d'amic e amat: «Hi he afegit també simplicitas i nobilitas, dues dignitats que seran incorporades a la figura A de l'Ars demostrativa, segona versió de l'Ars, en substitució d'humilitas i patientia» (Luzón 2012: 116, n. 19). La humildad en este opúsculo protagoniza numerosas sentencias morales con propósitos variados. Por una parte, se identifica con la esencia del amado: «No ha mon amat diferencia en humilitat, humil, humiliat, cor tot es humilitat en pura actualitat» (LAA, 315). Asimismo, la humildad guarda relación con el amigo y su pobreza (LAA, 266), con la contrición (LAA, 316) y con la necesidad de desembarazarse de todo lo material para tener acceso a la divinidad:

Lo lum de la cambra del amat vench inluminar la cambra del amich, per ço que.n gitás tenebres e que la umplís de plaers e de langors e de pensaments. E l'amich gitá de sa cambra totes coses per ço que hi cabés son amat (LAA, 96).

Finalmente, Na Renart no consigue ser incluida en el Consejo y decide vengarse del rey. Para ello trata de embaucar al Elefante, quien afirma confiar en el juicio del Gallo y de la Serpiente. De nuevo la zorra saca a relucir su ingenio y cuenta que un cristiano tenía un sarraceno en el que confiaba plenamente y este, «per ço cor era a ell contrari per lig, no li podia portar bona volentat, ans considerava tots jorns com l'auçiés» (LB, 230). Na Renart, por tanto, aprovecha una intemporal desconfianza religiosa para ilustrar la diferencia que le interesa, para esconder lo que se revela como una lucha de clases y crear en el Elefante la ilusión de una posibilidad de victoria. La atribución a los sarracenos de cualidades de potenciales intrigas, engaños, errores o falsedades aparece también en algunos versículos del Llibre d'amic e amat (LAA, 148, LAA, 328). Destacamos el siguiente en el cual hallamos, además, un recurso frecuente en la literatura luliana como es el de establecer vínculos entre sus propios textos:

—Digues, foll, en que has conexença que la fe catholica sia vera e la creença dels jueus e dels sserrayns sien en falsetat e error?

Respós: -En les .x. condicions del Libre del gentil e dels tres savis (LAA, 279).

El Elefante y Na Renart intercambian ejemplos mediante los cuales cada uno intenta reforzar su posición. El Elefante, vencido en sus argumentos o tan solo curioso por el momento, incide en la supuesta debilidad de la zorra, «tan pocha bestia et $a b \tan$ frevol poder» (LB, 232), lo que le sirve a esta para narrar una fábula con ecos clásicos: una liebre enfrenta a un león frente a su reflejo en 
un estanque y le dice que allí hay un segundo león que quiere ocupar su trono; el león se ahoga y la liebre se salva gracias a su astucia. El Elefante aún se resiste y replica con un exemplum sobre una pulga y un piojo y cómo la astucia puede conllevar la muerte. Finalmente, $\mathrm{Na}$ Renart conseguirá su compromiso para derrocar al rey con una comparación entre ella y la Serpiente: «Donchs, si la Serpent ab Eva tractá tant de mal, be-s pot esdevenir que yo, ab mon seny et ab ma çertea, pusca tractar que lo rey vingua en ira de son poble» (LB, 233).

Sus siguientes movimientos se dirigen hacia el Buey, a quien intercepta en una llanura cuando este viene hacia la Corte. El Buey repite una información conocida: el hombre quería comérselo y por eso regresa aun con los riesgos que conlleva su vuelta. Na Renart parece aquí como si rebajara su tono con «semblances» claras y sencillas. Lo vemos en el siguiente exemplum, donde un ermitaño baja de una montaña para aconsejar a un rey:

Et per açó yo son vengut a vos, e son devallat de mon hermitatge et prepós a estar ab vos tant longament, tro que vos e vostre regne siats en bon estament, dient a vos paraules de Deu per les quals hajats a Deu amor et hajats de Deu conexença et temor (LB, 236).

El «contra-arte» de la zorra se alimenta aquí de una confianza en la palabra divina que permita el conocimiento de Dios, utilidad que recuerda nuevamente al origen del Llibre d'amic e amat y sus «paraules d'amor e exemplis abreuyats» (Llull 2009: 427) mediante las cuales Blaquerna pretende elevar y sostener la devoción del hombre. El amigo reclama a su amado esta utilidad de la palabra y lo consigue, pues en «lo cor del amich fo audacia en loar son amat, e en sa boca foren laors de son amat» (LAA, 130). Se trata así de un movimiento de ida y vuelta en tanto que para él las palabras referidas a Dios suponen su conocimiento y, a la vez, pueden ser conocidas por su procedencia divina. La palabra motiva directamente su viaje por el mundo:

-Preycha, foll, e digues paraules de ton amat.

Plorá, dejuná, renunciá al mon l'amich e aná cerchar son amat ab amor. E loava-lo en aquells lochs on era desonrat (LAA, 273).

De esta manera la palabra se vuelve medio y fin. Sus posibilidades ascendentes y descendentes implican una circularidad y son propiciadas por el influjo divino que el amigo percibe a veces con imágenes de espejos (LAA, 341), mediante llaves y puertas (LAA, 42, LAA, 43) o cargado del mismo fervor y temor (LAA, 340) que espera inculcar el ermitaño al rey en el exemplum de $\mathrm{Na}$ Renart, quien se impacienta y no espera contestación por parte del Buey, sino que simplifica y resume: «Senyer En Bou, vos sots bestia semblant a l'hermitá» (LB, 236). Aquí comienza la puesta en práctica de la treta contra el rey y sus compañeros. Na Renart ordena al Buey que vaya a una pradera y que brame todo lo fuerte que pueda, tres veces por el día y tres por la noche, y luego se presenta en la Corte. Frente al miedo del resto de animales que oyen aquel bramido sin saber de dónde proviene, ella alardea de dos cualidades sobre las que 
se insistirá a lo largo del texto y que son piezas fundamentales de su «contraarte»:

Enaxí, senyer I-dix Na Renart al Leó-, yo he tanta de art e de maestria, que si.s esdevenia que non pogués vençre per força d'armes la bestia qui ha aquesta veu tan forts et tan terrible, aydar-me-n'hia per ma art e per maestria, en tal manera que la faria morir a mala mort (LB, 238).

La Serpiente, aludida en el ejemplo de Na Renart, contraataca con otro en donde precisamente el «art» y la «maestria» son causa de la muerte del que las practica, en este caso un airón que idea una estratagema para que los peces de un estanque confíen en él y se dejen transportar a otro lugar más seguro, puesto que el estanque, afirma el embaucador, se halla bajo el peligro de las redes del hombre. De esta manera: «Açò hac tengut l'agró longament et enaxí vivia sens treball de pescar» $(\mathrm{LB}, 239)$. La treta será descubierta por un cangrejo que matará al traidor, tildado explícitamente como tal: «Et lo cranch se·n torná a sos companyons, als quals recomptá la tració que.l agró los faya; per la qual tració l'agró fo occasió de sa mort» (LB, 239). En el Llibre d'amic e amat la holgazanería y la pereza señaladas por la Serpiente -y atribuidas de paso a Na Renartson absolutamente lo opuesto a la frenética actividad del amigo, a la fatiga inherente a su camino, a veces gozosa: «Demanaren a l'amich quals son los fruyts d'amor. Respós: -Plaers, cogitaments, I desigs, suspirs, ansies, treballs, perills, turments, languiments» (LAA, 70). La traición que apunta la Serpiente con carácter profético encuentra también su oposición en la lealtad exaltada por el amigo (LAA, 106) o reclamada como ocasión de «vergonya» (LAA, 117).

$\mathrm{Na}$ Renart ataca con ira a la Serpiente con algo de lo que no puede escapar: su maldad primigenia contra Eva. Sabe que es momento de ser efectiva y para ello se apoya en la ficción de otro ejemplo. Así, vuelve a recurrir al establecimiento de una línea vertical que va desde Dios al rey que con justicia debe gobernar a su pueblo por mandato divino, una línea en la que no hay espacio para quien representa lo contrario a Dios, es decir, la Serpiente, para la que se guarda un último golpe cargado de sarcasmo al recuperarse los atributos del «art» y la «maestria», pero ahora no como vías para la salvación -como era el caso con los bramidos del Buey-, sino como habilidades insuficientes: «Per les paraules que.l sant home hac dites al rey, aucís lo rey la serpent, sens que la serpent no hac art ni maestria que.s sabés ajudar de la mort» (LB, 240). Seguidamente, la zorra se ofrece para ir a hablar con el animal del terrible bramido y se reúne con el Buey, a quien le da un consejo fundamental para la trama posterior del Llibre de les bèsties como es que «recomptats al rey del estament dels homens et consellats al rey que haja amistat ab lo rey dels homens» $(\mathrm{LB}, 241)$. El Buey se presenta en la Corte, solicita el perdón real y se gana la atención de los demás animales con una declaración que sirve como segunda gran introducción a la figura del hombre: «la pus mala bestia et la pus falsa que sia en est mon, es home» (LB, 241). El Buey, entonces, narra un enrevesado exemplum que tiene algunas similitudes con uno reciente de Na Renart (LB, 238) - ¿suena su voz tras las palabras del Buey?- en donde también había presencia de un «corp», «la serpent», y la «garlanda» de la hija de un rey (LB, 242). A continua- 
ción, Na Renart confirma la avaricia y vanidad de los hombres y propone enviar regalos con unos mensajeros, algo con lo que todos están de acuerdo menos el Gallo, quien hace una advertencia al rey:

Si vos havets amistança ab lo rey dels homens et li trameltets missatges et ell vos tramet sos missatges, aquells missatges que ell vos trametrá conexeran en vostra persona et en vostres barons que, segons gin ni art, vos no us podets defendre al rey dels homens, qui.s combat ab art e ab engyin, ab que apodera tots aquells que per força se combaten sens art et maestria (LB, 243).

Las razones expuestas por el Gallo son diáfanas y pretenden cerrar el capítulo del «art», el «engyin» y la «maestria», pero la zorra no está dispuesta a ello y reacciona veloz para continuar en la línea de destrucción de sus propios atributos. La astucia está en entredicho y, por ello, es momento de sacrificarla:

De l'altra part allegá Na Renart e dix que Deus fa ço que fa ab poder sens art et maestria; et per açò coven que, segons natura, sien pus poderoses en la batalla tots aquells qui.s I combaten ab semblants armes d'aquelles de Deu, que cells que.s combaten ab dessemblants d'armes d'aquelles de Deu (LB, 244).

Como podemos apreciar ya no importa el arte, la astucia o la industria, sino todo lo contrario, siendo así que pueden vencer porque combaten sin estas herramientas, tal y como lo hace Dios, y como lo hacía a su vez el amigo en el Llibre d'amic e amat, sin más compañía que «fe, sperança, caritat, justicia, prudençia, fortituto, temprança» (LAA, 134) o solamente «ab les forçes de mon amat» (LAA, 195). El León se decanta por la opinión de Na Renart y pregunta quiénes son los más adecuados para ir como mensajeros al reino de los hombres y qué regalos deben enviar. Ella vuelve a intervenir para decir que conteste el Buey puesto que ha vivido entre ellos. Será esta una de las pocas veces a lo largo del Llibre de les bèsties en que nuestro personaje se aparte voluntariamente ante una decisión de tanto calado como la que aquí están tratando. La causa parece encontrarse en las propias palabras que dice el Buey y que se ajustan perfectamente a los intereses de la zorra, por lo que podríamos percibir otra vez sus garras bajo el discurso de aquel. El Buey propone -y así se hace- que mande como consejeros a la Pantera y al Leopardo y que lleve como presentes al Gato y al Perro, lo que sirve para que el Buey se convierta en camarero del rey y Na Renart ocupe el puesto de portero.

En las siguientes escenas la zorra sale de la trama del Llibre de les bèsties, que se centra en la visita de los mensajeros, quienes nada más llegar a la ciudad se topan con un burdel: «A l'entrant d'aquella ciutat sdevench que staven folles fembres de bordell et en presencia dels missatges peccaven ab los homens» (LB, 245). Como vemos se focaliza en la «locura» de estas mujeres y en la misma línea continúa un ejemplo del Leopardo sobre un burgués y su esposa. Creo 
no estar forzando las $\operatorname{cosas}^{5}$ cuando aprecio una cierta similitud entre esta «locura» y el amor ferino y bestial descrito por Marsilio Ficino (Figline Valdarno, Florencia, 1433-Careggi, Florencia, 1499) en De amore (1469) y en el parecido tono general del siguiente fragmento de la «Oratione VI», cap. VIII, «In tutti gli animi sono due amori, ne nostri ve ne sono cinque»:

Ogni amore adunque comincia dal vedere, ma l'amore de l'huomo contemplativo dal vedere passa nella mente; del voluttuoso dal vedere descende nel toccare; dell'attivo rimane nel vedere. L'amor di quello piu tosto al demone superno, che al basso si rivolge, di questo al basso, piu tosto che al superno si piega. De l'altro equalmente è lontano da l'una, l'altra distantia, questi tre amori si guadagnano tre nomi: l'amore de l'huomo contemplativo, divino; dell'attivo, humano; del voluttuoso, bestiale lo chiamiamo ${ }^{6}$ (Ficino 1544: 46).

Por su parte, la locura aparece en muchísimos versículos del Llibre d'amic $e$ amat, ya sea como atributo del amigo a través de las preguntas de otros (LAA, 82, LAA, 174, LAA, 346), calificación directa del amado (LAA, 68) o crítica hacia la alta clase eclesiástica tal y como vemos en la siguiente metáfora moral, donde el amigo, tildado de loco, ilustra lo que para él es la verdadera locura:

—Digues, foll, has vist home qui sia orat?

Respós que ell havia vist un bisbe qui avia a sa taula molts enabs e moltes scudelles e talladors d'argent, e havia en sa cambra moltes vestedures e gran lit, e en ses caxes molts diners. E a la porta de son palau havia pochs pobres (LAA, 284).

En la estancia de los animales en el reino de los hombres no nos detendremos mucho pues para nuestros fines es imprescindible la presencia de $\mathrm{Na}$ Renart, cuya ausencia se compensa con un catálogo de los vicios del rey humano, de su desprecio hacia los mensajeros en su tardanza al recibirlos -y cuando finalmente lo hace minusvalora los presentes del Perro y del Gato y la carta del

5 Como muestra de continuidad en la línea de investigación remito nuevamente al trabajo apuntado en la nota 2 en relación a las similitudes de aire neoplatónico entre el Llibre d'amic e amat y el De amore, en concreto en cuanto al papel de la imaginación y la fantasía como mediadoras en el reconocimiento y la creación del amor. Una experta lulista como F. A. Yates confirma la buena recepción de las obras de Ramon Llull durante el Renacimiento: «Un símptoma de la popularitat que arribaria a atènyer en ple Renaixement és l'interès que hi va mostrar Nicolau de Cusa. En el corrent neoplatònic del Renaixement, que creixia amb Ficino i Pico, el lul-lisme va prendre un lloc d'honor. Els neoplatònics del Renaixement hi podien reconèixer nocions afins a les seves $\mathrm{i}$ que els arribaven de fonts medievals que no menyspreaven per bàrbares, com feien, contràriament, els humanistes» (Yates 1985: 201).

6 «Por tanto, todo amor comienza por la vista. Pero el amor del hombre contemplativo asciende desde la vista a la mente. El del voluptuoso desciende de la vista al tacto. El del activo se queda en la mirada. El amor de aquél se dirige más al demonio superior que al inferior. El de ése se desvía más al inferior que al superior. El de este dista lo mismo de uno y otro. Estos tres amores toman tres nombres. El amor del contemplativo se llama divino, el del activo, humano, el del voluptuoso, bestial» (Ficino 2001: 141-142). 
León-, del dinero y la corrupción que parecen regir todos los intereses de aquel lugar supuestamente más civilizado, con juglares que, en ostentosos banquetes, cantan y loan lo que no debe ser, según el narrador, cantado o loado: «Aquells juglars loaven ço que faya a blasmar et blasmaven ço que faya a loar, et lo rey et la regina et tots los I altres reyien et havien plaher de ço que aquells juglars | fayen» (LB, 248). En nuestra lectura pasamos también rápidamente por la entrada de un «home vench pobrament vestit, ab gran barba, a aquella sala» ${ }^{7}$ (LB, 248) y por la piadosa intervención de un escudero, al que el rey prohíbe cantar para que no ponga en evidencia sus excesos y faltas, «en los quals se delitava et estar proposave tro a la fi de sos dies, en la qual fi proposave pendre penitençia de sos peccats» (LB, 249). Destacamos la absoluta conciencia del rey de contar con un as en la manga hasta el último instante en el que siempre podría arrepentirse, algo que aprovechamos en nuestra lectura para ofrecer el contraste del amigo y sus esforzados ejercicios de contrición:

Duptá l'amich que son amat no li falís a ses majors neçessitats. Desenamorá l'amat son amich. Ach contricció, penediment, l'amich en son cor. E.l amat reté al cor del amich sperança, caritat, e als hulls, lagremes e plors, per ço que retornás amor en l'amich (LAA, 49).

Tras el banquete los animales marchan a su posada y allí conocen la situación de un posadero y su acerada crítica al rey y su gobierno por convocar unas inútiles cortes que solamente empobrecen todavía más a sus súbditos. «L'oste» manifiesta que el mal príncipe hace daño dos veces: «la una es per lo mal que fa; l'altre es per lo be que fer poria, lo qual no fa» (LB, 251). Pasamos igualmente con premura por el nuevo encuentro entre el rey y los animales -que provocará un conflicto con posteriores consecuencias provocado por el mejor trato del rey hacia el Leopardo y la envidia de la Pantera- y por la aparición de los ocho prohombres que portan quejas respecto a los oficiales reales que destruyen sus tierras, quejas que caerán en saco roto. La conclusión final del Leopardo no deja lugar a dudas de la intencionalidad del pasaje: «En les paraules que lo Leopart hac hoydes, conech que 1 rey hauria pena en infern aytant gran com era lo dampnatge que.s seguiria tots temps en les males costumes que son malvat consell metia en la terra» (LB, 252). Se insiste así en la maldad del rey y de su Consejo, en sus malas costumbres que implican una penosa situación para sus súbditos. No hay en las palabras del Leopardo una crítica contra el orden feudal o una propuesta de revisión organizativa, sino una feroz condena de una mala gestión por parte de una clase dirigente sobre la que, atendiendo al pensamiento luliano, se exige su máxima ejemplaridad:

Son sobre todo las clases superiores -destacando el rey y el obispo, juntamente con sus subordinados- el centro de atención de los eximplis o semblances. Es en el obrar bueno o malo donde Llull exigirá a estas clases una conducta

${ }^{7}$ En este hombre, cuyas palabras inciden en el argumento de la primera intención, M. de Riquer ve una «fugaç aparició del mateix Ramon Llull» (Riquer 1964: 310). 
paradigmática, es decir, «donar bon eximpli o mal eximpli» (Ramis i Serra 1991: 160).

La propuesta luliana no se asienta, por tanto, en una idea de revolución político-social, pues «para Llull este ámbito práctico es secundario, dada su acaparación por el hecho religioso, $\mathrm{y}$, consiguientemente, el moral» (Butinyà 2008: 322-323). Es en la exigencia de ejemplaridad en donde se concentran sus requerimientos y su acerada crítica. Un salto en la narración nos lleva al pasado desde el punto de vista de Na Renart, poco más tarde de que los mensajeros marcharan hacia la corte del rey de los hombres. Es una breve actualización que nos resume lo sucedido en el reino de los animales en pocas líneas. Se focaliza en el hecho más importante como es la violación de la Leoparda por parte del León y con la ayuda y el empuje de las palabras de la zorra: «Na Renart, qui era porter del rey, dix al rey que lo Leopart havia la pus bella bestia per muller que fos en tot lo mon» (LB, 253). La violación se produce: «Tant loá Na Renart al rey la Leuparda, que lo rey s'enamorá de la Leuparda et pres aquella | per muller» (LB, 253). El Buey, entonces, expresa su temor ante el regreso del Leopardo y la suerte de la zorra que va ligada a la suya y esta contesta con un ejemplo de una doncella que comete una falta contra la reina y su incapacidad para actuar puesto que la doncella está en favor del rey. Poco después, Na Renart se incorpora al Consejo como siempre fue su objetivo y con la excusa de protección ante las posibles represalias del Leopardo, quien tilda al rey de traidor y lo avergüenza ante sus súbditos. La zorra elabora un torcido discurso en torno a la traición e implica a los demás con un hábil giro populista: «Traçió es cosa que es a Deu molt desagradable, et gran deshonor es a tot lo poble de rey que lur senyor sia apellat de tració» (LB, 256). A continuación, solicita algún barón que se enfrente con el Leopardo y será la Pantera, resentida tras el menor aprecio que recibió del rey de los hombres, la que se ofrezca para la batalla. La escena viene marcada por una afirmación previa a la lucha, adjudicada sin mayor concreción al «poble» en su conjunto: «Ara parrá qui vençrá, o veritat o falçetat» (LB, 256). La verdad se termina imponiendo y vence a la falsedad con la muerte de la Pantera, momento que aprovecha el León para eliminar al agotado vencedor de la contienda, lo cual provoca el veredicto de los animales:

Tots quants foren en la plaça del rey foren despagats del falliment que 1 rey havia fet et cascú desirá esser en senyoria d'altre rei, cor molt es perillosa cosa subjugaçió de poble qui sia sotsmés a rey injuriós, irós, traydor (LB, 257).

En el Llibre d'amic e amat los contrastes entre lo verdadero y lo falso coinciden a veces con referencias a los sarracenos, como señalábamos anteriormente, pero también hallamos juegos lingüísticos - «Anc ver no fo ço en que mon amat no fo, e fals es ço en que mon amat no es, e fals será ço en que mon amat no será» (LAA, 304) - y una batalla directa entre Verdad y Falsedad:

En .i. gran boscatge era l'almich, qui anava cerlchan son amat. E atrobá veritat e falsedad qui-s contrastaven de son amat, cor veritat lo loava e falsetat lo blasmava. E pero açó l'amich cridá amor que ajudás a veritat (LAA, 185). 
Las intrigas de $\mathrm{Na}$ Renart continúan y logra eliminar a sus principales rivales en el Consejo cuando convence al León para que sean los mejores ejemplares de su categoría, el Oso y el Lobo, los escogidos para ser enviados al rey de los hombres. Su jugada no concluye ahí sino que incluye en el paquete a la Serpiente, «lo pus savi missatge de sa cort» (LB, 257). El León, poco más que un muñeco de trapo en las garras de la zorra, accede y la Serpiente cuenta un exemplum antes de su marcha, pero el rey, de quien se indica su pérdida de juicio afectado por su pecado - «Lo Leó, depuix que fo en peccat et hac mort lo Leupart, no hac tanta de sobtilea ni de engin com d'abans havia» (LB, 258)- no entiende lo dicho por la Serpiente y esta se ve en la obligación de explicar su contenido acusatorio contra el Buey y Na Renart. El Buey se humilla ante el León y lo alaba por no comérselo. En su torrente de palabras acusa a la zorra y revela que fue ella la que le ordenó que bramase tres veces de día y tres de noche. La revelación pasa desapercibida para todos menos para la propia zorra, que ideará un plan para vengarse del Buey, lográndolo engañar para ofrecerse al León como alimento.

En otro golpe de efecto, $\mathrm{Na}$ Renart consigue ejercer un control casi total sobre el Consejo con el nombramiento del Conejo como camarero del rey. El único que permanece fuera de su influencia es el Gallo, quien recomienda aumentar el menguado número de consejeros. Na Renart relata un ejemplo de tono y contenido misógino que gira en torno al motivo del secreto y la necesidad de mantenerlo (LB, 262), es decir, su no revelación. El secreto tiene una importante presencia en el Llibre d'amic e amat (LAA, 149, LAA, 154, LAA, 280). Destacamos el siguiente versículo en donde el secreto ve unida su suerte a la predicación y al amor del amado en un juego de revelaciones:

Demanarem al foll on començá enans sa amor, o en los secrets de son amat o en revelar-los a les gents. Respós e dix que amor no y fa null departiment, cor es en son compliment; cor ab secret te l'amich secret los secrets de son amat, e ab secret los revela, e ab revelació los te secrets (LAA, 74).

En su exemplum Na Renart utiliza además un recurso de su predilección como es el de introducir a sus oponentes en sus ficciones, las cuales influyen en la realidad de su mundo animal y casi siempre en el sentido que pretendía. Su foco se sitúa esta vez en el Gallo, concluyendo tras el ejemplo que «lo Gall era tan savi que sabria aconsellar en totes coses» (LB, 263) y que no era necesario, por tanto, incrementar el número de consejeros. La contestación del Gallo no gusta al León y la circunstancia es aprovechada por Na Renart para matar al Gallo y hacerse con el control del Consejo. Sin embargo, el personaje parece encontrarse en una espiral que no puede o no quiere detener y, aunque se remarca su buena posición actual, prosigue con su plan de traición contra el rey. Para ello, habla con el Elefante, el cual mantiene ciertos escrúpulos y piensa en traicionarla con un razonamiento que apuntala la larga línea que cruza el Llibre de les bèsties respecto a las distintas valoraciones y los diferentes usos del arte, el ingenio, la maestría y también la traición: 
Dementre que-l Aurifany enaxí considerava, ell dix enfre si que enaxí com $\mathrm{Na}$ Renart ab maestria volia fer auçiure al rey, que enaxí ell ab maestria fes auçiure al rey Na Renart. «Cor, si en lo cors de Na Renart cap tració, çertea ni maestria, quant mes -dix l'Aurifany- en mor cor, qui es tan gran, deu caber lealtat, saviea et maestria» (LB, 265).

El Elefante cuenta al León los planes de Na Renart insistiendo con una idea que ya apuntábamos cuando el Caballo recomendaba al Buey que huyera del hombre y se sometiera a su destino en el reino de los animales y que ahora se traduce en un nuevo sometimiento pues el Elefante «amava mes esser leyal sotsmés que traydor rey» (LB, 267). Continuando en su nuevo papel, el Elefante recomienda al rey que «no sotsmetats a malvada persona la noblea que Deus vos ha donada per linatge I et per offiçi» (LB, 268), es decir, señala un influjo divino que toca a la nobleza y que asegura su privilegiada posición. Es así que el León, aun con todas sus faltas, delitos y continuas muestras de su incapacidad para gobernar y de la influencia que pueden llegar a ejercer sobre él sus consejeros, queda asentado y confirmado en su puesto. Relacionando este hecho con la escena anterior en la que el León mataba al Leopardo, con lo cual la batalla que había sido ganada por la Verdad se evidenciaba como una victoria de la Falsedad, podemos inferir que «la revelación de la verdad no implica que la victoria sea del que la mantiene. El realismo de Llull, que sabe que no vence el bien en el mundo, hace de ello una constante y da explicaciones contundentes de esa inversión, fundadas en la maldad de los hombres» (Butinyà 2004: 89, n. 39) ${ }^{8}$.

$\mathrm{Na}$ Renart intenta algunos últimos movimientos, pero su suerte está echada y el León la mata para tranquilidad de la Corte y de los consejeros, entre los que ahora se encuentran el Elefante y el Jabalí, pero no el Conejo o el Pavo, cerrándose este Llibre de les bèsties con el epílogo que citábamos con anterioridad y la vuelta de Fèlix a escena, quien continuará maravillándose hasta su descanso final en la abadía y sus últimas palabras reclamando alguien que pueda continuar con su causa: «Senyor Deus, I plaçia.t que, pus yo defall a complir aquest ofici, que Tu lo dons ha un altre qui-n sia pus digne de mi, et aquell complesca ço en que yo defall per merit et per abreujament de vida» (Llull, 2014: 334). El reclamo encuentra respuesta con el surgimiento del Segundo Fèlix, asegurándose la supervivencia y continuidad de este Llibre de meravelles en una ejemplarizante circularidad ${ }^{9}$, de tal forma que el «cavaller errant del començament, a la recerca de treballs i perills, s'és convertit en una mena de joglar recontador dels

8 Siguiendo la lectura del Llibre de les bèsties con la mirada puesta en los apostólicos como destinatarios del texto, J. Butinyà (2004) afirma que «es también ahí donde nos vemos obligados a desentrañar su vena satírica y donde pueden hallarse fecundas explicaciones, puesto que la fidelidad al señor que Llull estaría ilustrando sería la jerárquica, a la que necesitaba imperiosamente someterse aquella secta; recomendación que hace al amparo del símil feudal» (Butinyà 2004: 90).

9 En esta circularidad encuentra Riquer (1964) una explicación al nombre del protagonista del Llibre de meravelles al relacionarlo con el ave Fénix: «Però Llull no va voler donar al seu personatge el nom exacte del poètic ocell, Fènix, i només el varià en una lletra, sens dubte per acréixer-lo amb un altre significat: Fèlix, o sia "benaurat", amb la qual cosa es cristianitza el mite pagà» (Riquer 1964: 302). 
eximplis amb els quals Fèlix havia delitat l'abat i els monjos» (Rubió i Balaguer 1985: 317).

A modo de conclusión insistimos sobre las ascensiones tan distintas que Ramon Llull propone en el Llibre d'amic e amat y en el Llibre de les bèsties. Persiguiendo sus ansias de poder o dejándose llevar por un insaciable carácter vengativo, la escalada de Na Renart conlleva finalmente su muerte. Su ascensión pertenece al ámbito del poder terrenal y se ejemplifica en la elaboración de sus constantes y divertidas intrigas. Por su parte, la ascensión del amigo tiene un objetivo que se circunscribe al orden divino, con sus notas de circularidad y su constatación de una distancia aún por cubrir para alcanzar el amor del amado y sus «dignitats divines» y, en otras ocasiones, plenamente cubierta. El Llibre d'amic e amat como manual místico y el Llibre de les bèsties como «manual de sagesse politique» (Rubió i Balaguer 1985: 323) definen los diferentes objetivos de los textos y la posición antagónica de sus protagonistas. Los enfrentamientos entre Verdad y Falsedad, las valoraciones respecto a la locura o la ejemplaridad que el amigo reclama y que no suele encontrar, así como la falta de la misma en los comportamientos del León o del rey de los hombres nos han permitido apoyar nuestra propuesta comparativa, aunque con preferencia nos hemos detenido en las figuras opuestas del amigo y Na Renart. Señalamos en este sentido un último versículo con motivos relacionados cuando el amigo afirma: «-He amors, pensaments, plors, desirers, treballs, languiments, qui son mellors que emperis ni | regnats» (LAA, 170). El Arte en su versión cuaternaria guía el camino del amigo por el mundo y posibilita sus labores de predicación ad extra o ad intra y el acceso a la divinidad reconocida a través de las dignidades. Por otro lado, Na Renart se sirve de lo que hemos venido llamando «contra-arte», el cual se vale de los atributos principales de la zorra como son la astucia, el arte, la industria, el ingenio o la maestría -similares pero con matices-, siendo capaz de renegar de ellos cuando le conviene hacerlo. Su discurso cambiante le permite moverse con agilidad entre unos y otros y se sustenta, según se ha ido comentando, sobre algunas ideas y conceptos relacionados con el Arte luliano, los cuales se han tratado de poner en comparación con las aplicaciones del Arte en nuestro otro opúsculo, es decir, dentro de otro marco ficcional. De esta manera, se ha intentado mostrar el uso que hace la zorra de dignidades como la sencillez y la humildad, el papel del secreto, las atribuciones de error o engaño a los sarracenos, la confianza en la victoria frente a los enemigos sin mayores armas que el influjo divino, la insistencia en la primera intención con distintas vueltas de tuerca o la creencia en la palabra como orientadora hacia virtudes que conducen a la sabiduría. El «contra-arte» de Na Renart, pues, como reverso del Arte.

\section{BIBLIOGRAFIA}

Badia, L. + Santanach, J. + Soler, A. (2016) Ramon Llull as a vernacular writer: communicating a new kind of knowledge, Woodbridge, Tamesis.

Badia, L. + Santanach, J. + Soler, A. + Mensa, J. (2013) «L'accés dels laics al saber: Ramon Llull i Arnau de Vilanova», Literatura medieval (1). Dels orí- 
gens al segle XIV, L. Badia (dir.), Història de la Literatura Catalana I, À. Broch (dir.), Barcelona, Enciclopèdia Catalana, Barcino, Fundació Carulla, Ajuntament de Barcelona, pp. 373-509.

Badia, L. + Bonillo, X. + Gisbert, E. + Lluch, M. (2011) «Introducció» al Llibre de meravelles, v. I, Llibres I-VII, NEORL X, Palma, Patronat Ramon Llull.

Batllori, M. (1993) Ramon Llull i el lul.lisme, v. II, E. Duran (ed.), J. Solervicens (coord.), Valencia, Eliseu Climent.

Bonillo, X. (2015) «La traducción francesa medieval del Libro de maravillas de Ramon Llull (fr. 189 de la BNF) y su relación con la tradición manuscrita catalana», Revista de lenguas y literaturas catalana, gallega y vasca, XX, pp. 15-40.

Butinyà, J. (2016) «El Llibre de les bèsties de Ramon Llull i els apostòlics», Estudis Franciscans, v. 117, n. ${ }^{\circ} 461$, pp. 395-418.

- (2008) «El Libre de les bèsties de Llull y el comportamiento político». V congrés de la SOFIME, Universidad de Alcalá de Henares, El pensamiento político de la Edad Media, P. Roche (coord.), Madrid, Fundación Ramón Areces, 2010, pp. 321-332.

- (2006) Detrás de los orígenes del Humanismo: Ramon Llull, Madrid, Universidad Nacional de Educación a Distancia.

- (2004) «Sobre el escandaloso "Llibre de les bèsties" de Ramon Llull y su audiencia», Espacio, tiempo y forma, Serie III, Historia medieval, N. ${ }^{\circ}$ 17, pp. 79-94

Cruz Hernández, M. (1977) El pensamiento de Ramon Llull, Valencia, Fundación Juan March y Editorial Castalia.

Domínguez, F. (2007) «Una lectura del Llibre de meravelles como ars praedicandi», Caplletra, 43, pp. 131-160.

Ficino, M. (2001) De Amore. Comentario a «El Banquete» de Platón, R. de la Villa Ardura (trad. y ed.), Madrid, Tecnos.

- (1544) Il comento di Marsilio Ficino sopra il Conuito di Platone, et esso conuito (De amore), Venecia, Giovanni Farri \& fratelli.

Llull, R. (2014) Llibre de meravelles, v. II Llibres VIII-X, L. Badia (dir. y ed.) + X. Bonillo + E. Gisbert + A. Fernàndez Clot + M. Lluch (eds.), NEORL XIII, Palma, Patronat Ramon Llull.

- (2011) Llibre de meravelles, v. I, Llibres I-VII, L. Badia, X. Bonillo, E. Gisbert y M. Lluch (eds.), NEORL X, Palma, Patronat Ramon Llull.

- (2009) Romanç d'Evast e Blaquerna, A. Soler y J. Santanach (eds.), NEORL VIII, Palma, Patronat Ramon Llull.

Luzón Díaz, R. (2012) «Les dignitats divines al Llibre d'amic e amat, de Ramon Llull», Nuevos Estudios Multidisciplinares sobre Historia y Cultura Medieval: Fuentes, Metodología y Problemas, J. M. Cabrera y D. A. 
Reinaldos Miñarro (eds.), Murcia, Centro de Estudios Medievales de la Universidad de Murcia y EDITUM, pp. 107-120.

- (2010) «El funcionament de la memòria al Llibre d'amic e amat, de Ramon Llull», Randa, 65 (Miscel-lània Gabriel Llompart, V), Barcelona, Publicacions de 1'Abadia de Montserrat, pp. 29-54.

Ramis i Serra, P. (1991), «Llibre de les bèsties: el príncipe y la sociedad», Studia Lulliana 31/2, pp. 149-165.

Riquer, M. de (1964) Història de la literatura catalana, Vol. I, Barcelona, Ariel

Rubio, J. E. (1997) Les bases del pensament de Ramon Llull, Valencia-Barcelona, Institut Universitari de Filologia Valenciana, Publicacions de l'Abadia de Montserrat.

Rubió i Balaguer, J. (1985) Ramon Llull i el lul.lisme, Barcelona, Departament de Cultura de la Generalitat de Catalunya, Publicacions de l'Abadia de Montserrat.

Ruiz Simon, J. M. (2015) «Les «metàfores morals» de l'ermità Blaquerna. A propòsit de la manera i la matèria del Llibre d'amic e amat», eHumanistal IVITRA v. 8, A. Monogràfic I. Arts of Finding Truth: Approaching Ramon Llull, 700 Years Later, H. Berlin (coord.), pp. 68-85 (pdf).

Soler, A. + Santanach, J. (2009) «Introducció» al Romanç d'Evast e Blaquerna de Ramon Llull, NEORL VIII, Palma: Patronat Ramon Llull, pp. 19-76.

Yates, F. A (1985) Assaigs sobre Ramon Llull, Barcelona, Empúries.

Ysern i Lagarda, J. A. (1999) «Exempla i estructures exemplars en el primer llibre del Fèlix». Studia Lulliana, 39, pp. 25-54. 